\title{
Investigating the relationship between college students' acceptance of evolution and tree thinking understanding
}

\author{
Emily M Walter ${ }^{1 *}$, Kristy M Halverson ${ }^{2}$ and Carrie Jo Boyce ${ }^{2}$
}

\begin{abstract}
Background: Recent research suggests a relationship between understanding of macroevolutionary principles (such as phylogenetics) and acceptance of evolution in biology majors.

Method: The purpose of this study was to quantitatively investigate the relationship between ability to interpret phylogenetic trees (tree thinking) and acceptance of evolutionary theory for 92 university non-science majors before and after a general education biology course.

Results: We found that the majority of students taking the course held strong religious affiliations but were still open to having their mind changed and accepted evolution as a valid scientific theory. Students started and ended the course with a relatively high acceptance of evolutionary theory, but the nature of their acceptance changed significantly and we documented several such shifts. Additionally, we found a significant increase in students' tree thinking understanding after instruction and a slight, but significant, correlation between evolution acceptance and tree thinking understanding.
\end{abstract}

Conclusions: Our investigation demonstrated that targeted evolution instruction using a tree thinking approach may alter students' acceptance of evolution, even if the students initially hold strong anti-evolution ideas. By learning how college students understand and develop ideas about evolution using a visual approach, we can better target areas of confusion and begin forming guidelines for effective evolution instruction.

Keywords: Evolution education; Evolution acceptance; Tree thinking; Phylogenetic trees; College students

\section{Background}

Evolution is a central organizing principle of the biological sciences (American Association for the Advancement of Science (AAAS) 1993, 2011; Bybee 1997; Kagan 1992; National Association of Biology Teachers (NABT) 2010; National Research Council (NRC) 1996), and provides explanations for practical phenomena such as antibiotic resistance, the artificial selection of domesticated animals and food plants, and the diversity and history of life (AAAS 2011). Although there is little to no controversy surrounding evolution in the scientific community (Alters and Alters 2001), acceptance by the American public is largely lacking. A number of studies document

\footnotetext{
*Correspondence: emily.walter@wmich.edu

'Western Michigan University, 1903 W. Michigan Avenue, Kalamazoo, Ml 49008-3530, USA

Full list of author information is available at the end of the article
}

this issue; surveys generally report around one in three American adults firmly rejecting evolution, a significantly higher proportion than any western European country (Miller et al. 2006). Acceptance is slightly higher among Americans with some college education, with $49 \%$ accepting evolution for plants and non-human animals (but only $22 \%$ accept human evolution) (Lovely and Kondrick 2008). The general education biology course is a potential (and perhaps final) opportunity to influence evolution literacy for college educated individuals. It is therefore critical to understand how and what students learn about evolution in general education biology courses and how/if this knowledge is related to their evolution acceptance.

\section{空}

(C) 2013 Walter et al.; licensee Springer. This is an Open Access article distributed under the terms of the Creative Commons Attribution License (http://creativecommons.org/licenses/by/2.0), which permits unrestricted use, distribution, and reproduction in any medium, provided the original work is properly cited. 


\section{Literature review}

Several studies have hypothesized a link between knowledge and acceptance of evolution (for example, Anderson et al. 2002; Bishop and Anderson 1990; Demastes et al. 1995; Lord and Marino 1993; Nehm and Schonfeld 2008; Sinatra et al. 2003; Butler 2009). The outcome of these studies has been consistent: there is little or no relationship between knowledge of natural selection and acceptance of evolution. Furthermore, instruction seems to be limited to improving only knowledge of natural selection and not evolution acceptance (Bishop and Anderson 1990; Demastes et al. 1995; Jensen and Finley 1996; Asterhan and Schwarz 2007; Stover and Mabry 2007). A notable exception is Robbins and Roy (2007), who found significant changes in evolution acceptance instruction focused on evolution misconceptions and the evidence for evolution. However, psychometric tests to confirm the validity and reliability of the Robbins and Roy instruments were not published.

Although knowledge of natural selection has little influence on acceptance, knowledge of macroevolutionary content (deep time, speciation, common ancestry; Campbell and Reece 2005) may influence evolution acceptance (Nadelson and Southerland 2010a). Nadelson and Southerland document that evolution acceptance is correlated with knowledge of macroevolution $(\mathrm{r}[741]=$ 0.47, $P<0.01$ ) for biology majors (Nadelson and Southerland 2010b). Furthermore, knowledge of macroevolution $(\mathrm{t}[146]=2.77, P<0.01)$ and evolution acceptance $(\mathrm{t}[146]=3.38)$ significantly increase after a one-semester course, documenting a need to further investigate the impact of macroevolution coursework on student outcomes.

Our study examines students' knowledge of phylogenetics, a key subcomponent of macroevolution (Catley 2006; Nadelson and Southerland 2010a), that is often taught using phylogenetic (evolutionary) trees. Several authors have called for inclusion of phylogenetic trees in biology instruction (for example, Baum et al. 2005; Meir et al. 2007; Novick and Catley 2007). Unfortunately, trees are difficult for students as they have substantial visual conventions that are not particularly intuitive for novice readers (Halverson et al. 2011) (for example, Halverson et al. 2011; Gregory 2008; Naegle 2009; Perry et al. 2008). Poor content understanding, along with the non-intuitive nature of trees, can lead to students misinterpreting branching structures (Gregory 2008; Halverson 2011; Halverson et al. 2011; Novick and Catley 2012). These difficulties only add to the challenge of changing students' ideas about evolution (for example, Bishop and Anderson 1990; Demastes et al. 1995; Nehm and Reilly 2007). Considering these challenges and the correlational findings of Nadelson and Southerland (2010b), we approached this study with the goal of investigating students' knowledge of phylogenetic trees (hereafter referred to as tree thinking) and evolution acceptance before and after a general education biology course.

\section{Research questions}

The purpose of this study was to investigate the role of a general education biology course taught with a tree thinking approach on non-science majors' tree thinking understanding and acceptance of evolution. Specifically, we sought to address three questions: (1) What are students' views of evolution acceptance before and after the course?; (2) What are students' understandings of tree thinking before and after the course?; and (3) What is the relationship between evolution acceptance and understanding of tree thinking before and after the course?

\section{Methods}

Participants included 92 students enrolled in a general education biology course for non-science majors at a university in the southern United States. Only individuals who provided consent to participate in the study and completed all assessments were included in the study. We purposefully selected the general education biology classroom based on the instructor's background in both evolutionary biology and science education. She had five years of experience teaching evolutionary content with a tree thinking focus, including developing and using instructional interventions to target commonly held tree thinking misconceptions (Halverson 2010).

\section{Instructional approach of the course}

The 15-week course was divided into four units: Unit One, Nature of Science; Unit Two, Environment; Unit Three, Genetics; Unit Four, Evolution. The first three units were taught with a foundation in evolution, in an effort to help students be less resistant to the content presented in the evolution unit. The evolution unit (Unit Four) was five lectures in duration (each 75 minutes), and synthesized content from the three previous units. The instructional approach to this unit was unique in that the instructor used a tree thinking approach to present the material. A tree thinking approach is the process of frequently using phylogenetic tree images to help students understand the content (Baum and Smith 2012).

\section{Data collection}

We measured student pre/post acceptance of evolution and understanding of tree thinking with two tools: the Measure of Acceptance of the Theory of Evolution (MATE; Rutledge and Warden 1999) and the Tree Thinking Concept Inventory (TTCI; Naegle 2009). The MATE is a 20-item, 5-point Likert scale instrument that measures students' acceptance of evolution (20 (reject) - 
100 (accept)). The TTCI is a 26-item multiple choice instrument that measures students' understanding of phylogenetic trees. Both instruments are considered valid and reliable for use with undergraduate nonscience majors (Naegle 2009; Rutledge and Sadler 2007). In addition to the TTCI and MATE, we included an additional set of questions to qualify students' nature of evolution acceptance (NOA), identify demographics, document previous instruction on evolution and phylogenetic trees, and test confidence in responses. These questions are provided in Additional file 1: Appendix B.

The MATE instrument was used in its original form. We elected to modify the TTCI after analysis by two content experts. Nine scientifically inaccurate questions were eliminated, resulting in a modified TTCI with 17 multiple choice questions (Additional file 1: Appendix A). We also revised answer formats for TTCI questions that did not force a single correct response, that is, options that allowed for more than one correct answer (for example, 'more than one of the above'). Multiple correct answers did not function well for test administration over an electronic course management system. After revision, the modified version of the TTCI instrument was approved by Naegle and confirmed to have good reliability $(\alpha=0.707)$.

\section{Analysis}

We scored pre-/post-test student responses on the MATE and TTCI. Student responses on the MATE were scored in accordance to the Likert scale provided in the initial publication (Rutledge and Warden 1999). On the TTCI, students received 1 point for each answer that was the most scientifically accurate. After scoring student responses, the data were placed in SPSS 19.0 for quantitative analyses.

We first ran a line item analysis to look for trends in student responses and to identify item discrimination power as evidence for purposeful answer selections. We subsequently ran a paired-sample $t$-test to identify if there were significant differences in responses pre/post instruction on each assessment. Third, we ran a crosstabs analysis to determine the chi-squared valued related to students' confidence in their responses. We also ran Pearson's correlations among students' acceptance of evolution, the nature of their acceptance, and their tree thinking scores. Effect sizes were also calculated for the pre- and post-test scores to provide an additional meaningful measure.

\section{Results}

\section{Students' acceptance of evolution}

We hypothesized that there would be a low level of acceptance of evolution prior to the course (that is, below 60 on the scale of 20 (reject) to 100 (accept)), since the course was held in the 'Bible Belt' of the American south and the majority of students claimed to hold strong religious beliefs. However, we found that the majority of students had above average acceptance of evolution (per classifications of Rutledge 1996). Student acceptance was above neutral, at $64.9 \pm 13.9$ before the course and remained so after the course $(65.9 \pm 13.9)$ (see Table 1). There was no statistical significance in the 1-point increase between the pre- and post-course MATE scores. Upon analysis of specific questions to related to acceptance (NOA), we found that the majority of students $(72 \%)$ held a theistic view of evolution (for example, 'I believe evolution happened, but I also believe God created all life on Earth') throughout the course.

Students had a significant shift $(t(91)=2.427, P=0.017)$ in the overall nature of their acceptance (NOA) from the beginning of the course (Pre-NOA) to after the course (Post-NOA) on particular questions. For example, 9\% of students held the belief that 'evolution does not happen as scientists claim' and did not expect to have their mind changed. However, by the end of the course, this response dropped to $3 \%$ with only one individual selecting the same response on both assessments.

Students also shifted ideas about common ancestry to be more in line with scientific understanding (30\% preinstruction to $42 \%$ selecting the scientifically accurate response post-instruction). Before the class, $38 \%$ did not think there was a common ancestor between humans and apes. By the end of the course, the majority of students (70\%) thought that evolution provided evidence of a common ancestor connecting human and ape lineages. Furthermore, $48 \%$ of all students understood that that this shared ancestor was neither human nor ape, and no students claimed that evolution provided evidence that humans evolved from apes.

\section{Students' tree thinking}

There was a statistically significant increase $(t(91)=2.254$, $P=0.027$ ) in tree thinking scores (maximum score of 17) between the pre-TTCI and post-TTCI (Table 1). Item discrimination power ranged from -0.174 to 0.065 on the preTTCI. This result indicated high level of students randomly choosing (guessing) their responses. After the course, item discrimination power ranged from 0.130 to 0.370 on the post-TTCI. Students also self-reported that they gained confidence in answering questions regarding phylogenetics after instruction $\left(\chi^{2}(4)=24.87, P<0.001\right)$. Thus, we conclude that students relied less upon guessing at the end of the course when answering tree thinking questions.

\section{Relationship between acceptance of evolution and tree thinking}

We searched for a relationship between students' pre-/ post-MATE and pre-/post-TTCI scores. We found a 
Table 1 Student scores pre- and post-instruction in a general education biology course with focus on tree thinking

\begin{tabular}{|c|c|c|c|c|c|c|c|c|c|c|}
\hline & Pair & Mean & $n$ & SD & SEM & $d f$ & $t$ & Sig (2-tailed) & Cohen's $d$ & Effect size $r$ \\
\hline \multirow[t]{2}{*}{1} & Pre-MATE & 64.93 & 92 & 13.817 & 1.441 & 91 & 0.978 & 0.331 & 0.074 & 0.037 \\
\hline & Post-MATE & 65.90 & 92 & 12.354 & 1.288 & & & & & \\
\hline \multirow[t]{2}{*}{2} & Pre-TTCl & 5.46 & 92 & 2.959 & 0.309 & 91 & 2.254 & $0.027^{\mathrm{a}}$ & 0.294 & 0.145 \\
\hline & Post-TTCl & 6.37 & 92 & 3.240 & 0.338 & & & & & \\
\hline \multirow[t]{2}{*}{3} & Pre-NOA & 1.40 & 92 & 1.130 & 0.118 & 91 & 2.427 & $0.017^{a}$ & 0.365 & 0.179 \\
\hline & Post-NOA & 1.84 & 92 & 1.278 & 0.133 & & & & & \\
\hline
\end{tabular}

${ }^{\mathrm{a}}$ Significance at $<0.05$.

MATE: Measure of Acceptance of the Theory of Evolution (Rutledge and Sadler, 1999); NOA: questions related to the Nature of Acceptance of evolution as developed by authors; SD: Standard deviation; SEM: Standard error of the mean; TTCI: Tree thinking Concept Inventory (Naegle 2009).

significant, high correlation effect $(r=0.74)$ between the pre-MATE and post-MATE $(P<0.01)$. We also found low correlation effects (significance at $P<0.05$ ) for the following relationships (Table 2): pre-TTCI and post-TTCI $(r=0.21)$; pre-TTCI and pre-MATE $(r=0.21)$; pre-TTCI and post-MATE $(r=0.26)$; post-TTCI and post-MATE $(r=0.22)$. When we tested for correlations with the additional questions addressing the nature of students' acceptance pre-NOA and post-NOA, student NOA responses were correlated with their pre-MATE $(r=0.30, P<0.01)$ and post-MATE scores $(r=0.24, P>0.05)$.

\section{Discussion}

Student acceptance of evolution is most often considered a product of an individual's views of science and religion.
Although students from this study were from the American south, in a state where $58 \%$ of the population considers themselves 'very religious' (Newport 2013), most were open to being convinced that evolution was valid in spite of initially rejecting evolution (NOA Question 2, Response B). This is contrary to what some studies suggest about the stability of evolution acceptance among religious individuals (Demastes et al. 1995; Downie and Barron 2000; Lawson and Worsnop 1992; Woods and Scharmann 2001). Furthermore, the subset of the students who did not expect for their views to change still made shifts toward evolution acceptance. These individuals became both more likely to accept that evolution occurs as scientists claim and more likely to agree that humans and chimpanzees share a common ancestor.

Table 2 Correlations among student responses on data collection instruments

\begin{tabular}{|c|c|c|c|c|c|c|c|}
\hline & & Pre-TTCI & Post-TTCI & Pre-NOA & Post-NOA & Pre-MATE & Post-MATE \\
\hline \multirow[t]{3}{*}{ Pre-TTCl } & Correlation & 1 & & & & & \\
\hline & Sig & & & & & & \\
\hline & N & 92 & & & & & \\
\hline \multirow[t]{3}{*}{ Post-TTCI } & Correlation & $0.22^{\mathrm{a}}$ & 1 & & & & \\
\hline & Sig & 0.04 & & & & & \\
\hline & $\mathrm{N}$ & 92 & 92 & & & & \\
\hline \multirow[t]{3}{*}{ Pre-NOA } & Correlation & 0.08 & -0.04 & 1 & & & \\
\hline & Sig & 0.45 & 0.72 & & & & \\
\hline & $\mathrm{N}$ & 92 & 92 & 92 & & & \\
\hline \multirow[t]{3}{*}{ Post-NOA } & Correlation & 0.08 & 0.16 & -0.02 & 1 & & \\
\hline & Sig & 0.46 & 0.14 & 0.89 & & & \\
\hline & N & 92 & 92 & 92 & 92 & & \\
\hline \multirow[t]{3}{*}{ Pre-MATE } & Correlation & $0.21^{\mathrm{a}}$ & 0.03 & $0.30^{\mathrm{b}}$ & 0.15 & 1 & \\
\hline & Sig & 0.05 & 0.81 & 0 & 0.17 & & \\
\hline & $\mathrm{N}$ & 92 & 92 & 92 & 92 & 92 & \\
\hline \multirow[t]{3}{*}{ Post-MATE } & Correlation & $0.26^{\mathrm{a}}$ & $0.22^{\mathrm{a}}$ & $0.24^{a}$ & 0.11 & $0.74^{\mathrm{b}}$ & 1 \\
\hline & Sig & 0.01 & 0.04 & 0.02 & 0.30 & 0 & \\
\hline & $\mathrm{N}$ & 92 & 92 & 92 & 92 & 92 & 92 \\
\hline
\end{tabular}

${ }^{a}$ Significance at $<0.01$ level (2-tailed).

${ }^{\mathrm{b}}$ Significance at $<0.05$ level (2-tailed).

MATE: Measure of Acceptance of the Theory of Evolution (Rutledge and Warden, 1999); NOA: questions related to the Nature of Acceptance of evolution as developed by authors; TTCI: Tree Thinking Concept Inventory (Naegle 2009). 


\section{Shifts in the nature of acceptance}

The shift in the nature of student attitudes about evolution is promising. Some authors note that rejection of evolution can serve as a barrier to developing knowledge about it (Coburn 1994; Coburn Scharmann 1990). Other research has shown that rejection of evolution does not affect the ability to learn about natural selection (Bishop and Anderson 1990; Demastes et al. 1995; Sinatra et al. 2003). Our research supports this latter group of research. Although significant changes in evolution acceptance were not seen between pre- and post-MATE scores, our study documents students overcoming common misconceptions about common ancestry. For example, students were far more likely (7 out of 10) than the average American citizen (approximately 4 out of 10; Newport 2009; Scott 1997) to claim that there was a common ancestor connecting humans and higher apes.

\section{Factors influencing acceptance}

There was no significant gain in students' overall evolution acceptance and a low correlation between students' tree thinking understanding and acceptance of evolution. There are several possible reasons for disparaging statistics, including a possible ceiling effect, the nature of conceptual change, psychological factors related to evolution acceptance, or the nature of the TTCI instrument.

One of the reasons we did not see a significant shift in the overall acceptance of the students (as measured by the MATE) may be due to a ceiling effect. Students could have been hesitant to select statements with extreme adjectives (strongly agree/disagree) on the Likert scale (Pollack et al. 1990), creating a ceiling effect by decreasing the number of individuals with high MATE scores.

The lack of change in evolution acceptance scores may also be due to the nature of conceptual change. Conceptual change takes a long time, perhaps years, depending on the concept (Sadler 1998). Furthermore, complete conceptual change is unlikely, as most students do not completely 'replace' old ideas with scientific ones (Dole and Sinatra 1998; Ingram and Nelson 2006).

Another reason for our modest results could be psychological factors related to evolution acceptance. These factors include cognitive biases (Evans 2000, 2008; Gelman 2003; Medin and Atran 2004; Wellman and Gelman 1998), intellectual development barriers (Lawson et al. 2000), dispositional and motivational barriers (Brem et al. 2003; Sinatra et al. 2003), epistemological beliefs (Vosniadou and Brewer 1992), and religious beliefs (Almquist and Cronin 1988; Hokayem and BouJaoude 2008; Sinclair et al. 1997). The purpose of this study was not to investigate these factors; rather, we acknowledge their likely influence on this population and note that these factors likely contributed more to the variance of students' acceptance of evolution than their tree thinking understanding.

\section{Hypothesizing the influence of instruction}

As we do not have student interview data, we cannot claim that the changes in evolutionary acceptance documented in the study are a product of instruction. However, literature suggests that the some of the strategies used in the course can produce conceptual change in students. These include strategies that specifically address misconceptions (Abraham et al. 2009; Bishop and Anderson 1990; Demastes et al. 1996), active learning strategies (Abraham et al. 2009; Nehm and Reilly 2007), and nature of science instruction (Butler 2009; Southerland \& Sinatra 2003).

\section{Myth busting}

One of the misconception-targeted strategies in the course was a 'Myth Busters' session during Units One (Nature of Science) and Four (Evolution). The myth busting sessions presented students with the opportunity to work through known misconceptions about the nature of science, evolution, and phylogenetic trees. This may have been similar to the focus on evolution misconceptions described by Robbins and Roy (2007), who also documented shifts in evolution acceptance with instruction. Our approach was unique in that multiple units of the course were taught with evolution as a foundation, and students may have been less resistant to evolution instruction because of this.

\section{Active learning through a pipe cleaner activity}

Another strategy which may have influenced students' learning was the use of a pipe cleaner manipulative model during Unit Four. This is a direct form of tree thinking instruction as students are actively manipulating colored pipe cleaners as phylogenetic trees; each pipe cleaner represents a different lineage, tied together at nodes and at the root to represent common ancestry. Active learning strategies such as these can help students with the difficult visual conventions of trees and therefore assist them in overcoming misconceptions about evolutionary relatedness among taxa (see Halverson 2010 for information about this pedagogical approach).

\section{Nature of science instruction}

A better understanding of nature of science allows students to remove themselves from dualistic (right/ wrong) thinking about religion and science to more carefully consider multiple explanations (Southerland and Sinatra 2003). Additionally, teaching nature of science the content is positively correlated with knowledge of natural selection (Butler 2009). Subsequently, the nature of science unit (Unit One) may have had an 
influence on students' evolution acceptance and knowledge of phylogenetic trees. Although nature of science was reintroduced in the evolution unit, we consider nature of science instruction separate from our 'tree thinking' approach to teaching evolution, and therefore separate its potential influence on factors examined in this study.

\section{Other influences of instruction}

It is possible that the design of the course itself may have negatively contributed to the correlations between acceptance and tree thinking and/or contributed to the lack of significant gains in overall evolution acceptance. Without participant interviews, it is difficult to determine if students actively related their knowledge of phylogenetic trees to their personal acceptance of evolution. We therefore reserve judgment in this capacity. Instead, we recommend that future studies take a mixed methods approach to document both the extent of the instructional influence on student outcomes and how and why instruction was influential from the perspective of the students.

\section{Conclusions}

This study found that tree thinking instruction may improve evolution acceptance among non-science majors. In this section, we consider specific implications for how these results may influence post-secondary biology instruction and future science education research.

\section{For college biology instructors}

We saw significant differences in beliefs about common ancestry after instruction focused on (a) how to interpret phylogenetic trees and (b) how trees depicted common ancestry. These shifts in belief support the inclusion of macroevolutionary concepts in the general education biology course (Catley 2006). We therefore recommend that instructors of general education biology courses consider using phylogenetic trees to introduce evolution, explore evolutionary relationships, and to describe speciation/modification events. This approach should include a focus on misconceptions about evolution (especially common ancestry) and a discussion of the nature of science as related to evolution. As instructors teach students about phylogenetic trees, we also recommend the use of physical models, such as manipulative trees made of pipe cleaners (Halverson 2010), to help students overcome misconceptions about relatedness of taxa.

\section{For future research}

Due to the small and quantitative nature of this study, our next step is to expand the dataset to include data from subsequent semesters. Interviews with students should also be included to determine the influence of specific forms of instruction on students' ideas about phylogenetic trees and evolution acceptance.
A better instrument to measure understanding of phylogenetic trees should be developed. The original development of the TTCI did not include a factor analysis, and so the instrument may be redundant or have subcomponents worth reorganizing. We addressed content validity by using only the portion of the instrument deemed accurate by our two content experts but did not make note of the incorrect use of terms (for example, the paraphyletic term 'ape') until after the test had been administered. Although the revised instrument remains imperfect, since the psychometrics were good, the TTCI gives a broad (and the only available measure) for measuring knowledge of phylogenetic trees.

As a side note, we question whether the TTCI assesses content at a level appropriate for non-science majors. It is not surprising that this population performs well below experts, but it forces us to question what tree thinking skills one would expect for scientifically literate individuals (that is, what skills are needed to interpret the phylogenetic trees presented in lay media?). Researchers and instructors should work together to build an appropriate tree thinking diagnostic test by considering the known misconceptions about tree thinking (see Gregory 2008) through the lens of tree thinking literacy for the average educated individual.

Our final consideration for future research relates our work to research in intellectual development and evolution learning (for example, Lawson et al. 2000; Lawson and Thompson 1988; Southerland and Sinatra 2003, 2005; Southerland et al. 2001). Acceptance of evolution as a valid explanation of the natural world requires multiplistic epistemology (Perry 1970) for individuals who are strongly religious (that is, these individuals must have the ability to recognize the validity of multiple viewpoints). Most students enter college with dualistic epistemologies and therefore view the world as right or wrong (Pascarella and Terenzini 2005). Although students usually reach a level of multiplistic epistemology by the time they graduate (Pascarella and Terenzini 2005), general education courses are often completed during freshman and sophomore year. A future step in research would be to investigate evolution acceptance and ability to interpret phylogenetic trees as related to epistemological development among religious students in general education course settings.

\section{Additional file}

Additional file 1: Appendix A. Modified Tree Thinking Concept Inventory (TTCl). Appendix B Nature of Acceptance (NOA) questions.

Competing interests

The authors declare that they have no competing interests. 


\section{Authors' contributions}

EW brought knowledge of the evolution education literature, interpreted results as related to the literature, and wrote the majority of the manuscript. $\mathrm{KH}$ was the instructor of the course, designed the nature of acceptance questions, served as a phylogenetics content expert, and provided expertise in the tree thinking education literature. CB provided data analysis and wrote the methods section. All authors read and approved the final manuscript.

\section{Author details}

${ }^{1}$ Western Michigan University, 1903 W. Michigan Avenue, Kalamazoo, MI 49008-3530, USA. ²Department of Biological Sciences, 118 College Drive, Box \#5018, Hattiesburg, MS 39406, USA.

\section{Received: 14 August 2013 Accepted: 14 August 2013} Published: 09 Sep 2013

\section{References}

Abraham, JK, Meir, E, Perry, J, Herron, JC, Maruca, S, \& Stal, D. (2009). Addressing undergraduate student misconceptions about natural selection with an interactive simulated laboratory. Evolution: Education and Outreach, 2, 393-404.

Almquist, AJ, \& Cronin, JE. (1988). Fact, fancy and myth on human evolution. Current Anthropology, 29, 520-529.

Alters, BT, \& Alters, SM. (2001). Defending evolution: A guide to the creation/ evolution controversy. Sudburg, MA: Jones and Bartlett Publishers.

American Association for the Advancement of Science (AAAS). (1993). Benchmarks for science literacy: A Project 2061 report. New York, NY: Oxford University Press.

American Association for the Advancement of Science (AAAS). (2011). Vision and change in undergraduate biology education: A call to action. Washington, DC: AAAS.

Anderson, DL, Fisher, KM, \& Norman, GL. (2002). Development and evaluation of the conceptual inventory of natural selection. Journal of Research in Science Teaching, 39, 952-978.

Asterhan, CSC, \& Schwarz, BB. (2007). The effects of monological and dialogical argumentation on concept learning in evolutionary theory. Journal of Educational Psychology, 99, 626-639.

Baum, DA, \& Smith, SD. (2012). Tree thinking: An introduction to phylogenetic biology. Greenwood Village, CO: Roberts and Company Publishers.

Baum, DA, DeWitt-Smith, S, \& Donovan, SSS. (2005). The tree-thinking challenge. Science, 310, 979-980.

Bishop, BA, \& Anderson, CW. (1990). Student conceptions of natural selection and its role in evolution. Journal of Research in Science Teaching, 27, 415-427.

Brem, SK, Ramsey, M, \& Schindel, J. (2003). Perceived consequences of evolution: College students perceive negative personal and social impact in evolutionary theory. Science Education, 87, 181-206.

Butler, W. (2009). Does the nature of science influence college students' learning of biological evolution? (PhD dissertation). Tallahassee, FL: Florida State University.

Bybee, RW. (1997). Achieving scientific literacy: From purpose to practices. Portsmouth, $\mathrm{NH}$ : Heinemann.

Campbell, NA, \& Reece, JB. (2005). Biology (7th ed.). San Francisco, CA: Pearson Benjamin Cummings.

Catley, KM. (2006). Darwin's missing link - A novel paradigm for evolution education. Science Education, 90, 767-783.

Coburn, WW. (1994). Belief, understanding, and the teaching of evolution. Journal of Research in Science Teaching, 31, 583-590.

Demastes, SS, Settlage, J, \& Good, RG. (1995). Students' conceptions of natural selection and its role in evolution: cases of replication and comparison. Journal of Research in Science Teaching, 32, 535-550.

Demastes, SS, Good, RG, \& Peebles, P. (1996). Students' conceptual ecologies and the process of conceptual change in evolution. Science Education, 79, 637-666.

Dole, JA, \& Sinatra, GM. (1998). Reconceptualizing change in the cognitive construction of knowledge. Educational Psychologist, 33, 109-128.

Downie, JR, \& Barron, NJ. (2000). Evolution and religion: attitudes of Scottish first year biology and medical students to the teaching of evolutionary biology. Journal of Biological Education, 34, 139-146.

Evans, EM. (2000). The emergence of beliefs about origins of species in schoolage children. Merrill-Palmer Quarterly: A Journal of Developmental Psychology, $46,221-254$
Evans, EM. (2008). Conceptual change and evolutionary biology: A developmental analysis. In S. Vosniadou (Ed.), International handbook of research on conceptual change (pp. 263-295). New York, NY: Routledge.

Gelman, SA. (2003). The essential child: Origins of essentialism in everyday thought. Oxford: Oxford University Press.

Gregory, RT. (2008). Understanding evolutionary trees. Evolution: Education and Outreach, 1, 121-137.

Halverson, KL. (2010). Using pipe cleaners to bring the tree of life to life. The American Biology Teacher, 72, 223-224.

Halverson, KL. (2011). Improving tree-thinking one learnable skill at a time. Evolution: Education and Outreach, 4, 95-106.

Halverson, KL, Pires, CJ, \& Abell, SK. (2011). Exploring the complexity of tree thinking expertise in an undergraduate systematics course. Science Education, 95, 794-823.

Hokayem, H, \& BouJaoude, S. (2008). College students' perceptions of the theory of evolution. Journal of Research in Science Teaching, 45, 395-419.

Ingram, E, \& Nelson, C. (2006). Relationship between achievement and students' acceptance of evolution or creation in an upper-level evolution course. Journal of Research in Science Teaching, 43, 7-24.

Jensen, MS, \& Finley, FN. (1996). Changes in students' understandings of evolution resulting from different curricular and instructional strategies. Journal of Research in Science Teaching, 33, 879-900.

Kagan, DM. (1992). Implications of research on teacher belief. Educational Psychologist, 27, 65-90.

Lawson, AE, \& Thompson, LE. (1988). Formal reasoning ability and misconceptions concerning genetics and natural selection. Journal of Research in Science Teaching, 25, 733-746.

Lawson, AE, \& Worsnop, WA. (1992). Learning about evolution and rejecting a belief in special creation: effects of reflective reasoning skill, prior knowledge, prior belief and religious commitment. Journal of Research in Science Teaching, 29, 143-166.

Lawson, AE, Alkhoury, S, Benford, R, Clark, BR, \& Falconer, KA. (2000). What kinds of scientific concepts exist? Concept construction and intellectual development in college biology. Journal of Research in Science Teaching, 37, 996-1018

Lord, TR, \& Marino, S. (1993). How university students view the theory of evolution. Journal of College Science Teaching, 22, 353-357.

Lovely, EC, \& Kondrick, LC. (2008). Teaching evolution: challenging religious preconceptions. Integrative and Comparative Biology, 48, 164-174.

Medin, D, \& Atran, S. (2004). The native mind: biological categorization and reasoning in development and across cultures. Psychological Review, $111,960-983$.

Meir, E, Perry, J, Herron, JC, \& Kingsolver, J. (2007). College students' misconceptions about evolutionary trees. The American Biology Teacher, $69,71-76$.

Miller, JD, Scott, E, \& Okamoto, S. (2006). Public acceptance of evolution. Science, $313,765-766$

Nadelson, LS, \& Southerland, SA. (2010a). Development and evaluation for a measuring understanding of macroevolutionary concepts: Introducing the MUM. The Journal of Experimental Education, 78, 151-190.

Nadelson, LS, \& Southerland, SA. (2010b). Examining the interaction of acceptance and understanding: how does the relationship change with a focus on macroevolution. Evolution: Education and Outreach, 4, 82-88.

Naegle, E. (2009). Patterns of thinking about phylogenetic trees: A study of student learning and the potential of tree-thinking to improve comprehension of biological concepts (PhD dissertation). Pocatello, ID: Idaho State University.

National Association of Biology Teachers (NABT). (2010). Mission statement. http://www.nabt.org/websites/institution/index.php?p=1.

National Research Council (NRC). (1996). National science education standards. Washington, DC: National Academy Press.

Nehm, RH, \& Reilly, L. (2007). Biology majors' knowledge and misconceptions of natural selection. BioScience, 57, 263-272.

Nehm, RH, \& Schonfeld, I. (2008). Measuring knowledge of natural selection: a comparison of the CINS, an open-response instrument, and an oral interview. Journal of Research in Science Teaching, 45, 1131-1160.

Newport, F. (2009). On Darwin's birthday, only 4 in 10 believe in evolution. Retrieved from http://www.gallup.com/poll/114544/Darwin-Birthday-BelieveEvolution.aspx.

Newport, F. (2013). Mississippi maintains hold as most religious U.S. state. Gallop Politics. http://www.gallup.com/poll/160415/mississippi-maintains-holdreligious-state.aspx. 
Novick, LR, \& Catley, KM. (2007). Understanding phylogenies in biology: the influence of a Gestalt perceptual principle. Journal of Experimental Psychology Applied, 13, 197-223.

Novick, LR, \& Catley, KM. (2012). Assessing students' understanding of macroevolution: concerns regarding the validity of the MUM. International Journal of Science Education, 34, 2679-2703.

Pascarella, ET, \& Terenzini, PT. (2005). How college affects students. Volume 2. A third decade of research. San Francisco, CA: Jossey-Bass.

Perry, WG. (1970). Forms of ethical and intellectual development during the college years: A scheme. New York, NY: Holt, Rinehart, \& Winston, Inc.

Perry, J, Meir, E, Herron, JC, Maruca, S, \& Stal, D. (2008). Evaluating two approaches to helping college students understand evolutionary trees through diagramming tasks. CBE Life Sciences Education, 7, 193-201.

Pollack, S, Friedman, HH, \& Presby, L. (1990). Two salient factors in the construction of rating scales: Strength and direction of anchoring adjectives. Tucson, AZ: Paper presented at the International Conference of Measurement Errors in Surveys.

Robbins, JR, \& Roy, P. (2007). Identifying and correcting non-science student preconceptions through an inquiry-based critical approach to evolution. The American Biology Teacher, 69, 460-466.

Rutledge, ML. (1996). Indiana high school biology teachers and evolutionary theory: Acceptance and understanding (Unpublished PhD dissertation). Muncie, IN: Ball State University.

Rutledge, ML, \& Sadler, KC. (2007). Reliability of the Measure of Acceptance of the Theory of Evolution (MATE) with university students. The American Biology Teacher, 69, 332-335.

Rutledge, ML, \& Warden, MA. (1999). The development and validation of the Measure of Acceptance of the Theory of Evolution instrument. School Science and Mathematics, 99, 13-18.

Sadler, PM. (1998). Psychometric models of student conceptions in science: reconciling qualitative studies and distractor-driven assessment instruments. Journal of Research in Science Teaching, 15, 265-296.

Scharmann, JC. (1990). Enhancing an understanding of the premises of evolutionary theory: the influence of a diversified instructional strategy. School Science and Mathematics, 90, 91-100.

Scott, EC. (1997). Antievolution and creationism in the United States. Annual Review Anthropology, 26, 263-289.

Sinatra, GM, Southerland, SA, McConaughy, F, \& Demastes, JW. (2003). Intentions and beliefs in students' understanding and acceptance of biological evolution. Journal of Research in Science Teaching, 40, 510-528.

Sinclair, A, Pendarvis, MP, \& Baldwin, B. (1997). The relationship between college zoology students' beliefs about evolutionary theory and religion. Journal of Research and Development in Education, 30, 118-125.

Southerland, SA, \& Sinatra, GM. (2003). Learning about biological evolution. In G. M. Sinatra \& P. R. Pintrich (Eds.), Intentional conceptual change. Mahwah, $\mathrm{NJ}$ : Lawrence Erlbaum Associates.

Southerland, SA, \& Sinatra, GM. (2005). Beyond Cartesian dualism: Encountering affect in the teaching and learning of science. Amsterdam: Springer.

Southerland, SA, Sinatra, GM, \& Matthews, MR. (2001). Belief, knowledge, and science education. Educational Psychology Review, 13, 325-351.

Stover, SK, \& Mabry, ML. (2007). Influences of teleological and Lamarckian thinking on student understanding of natural selection. Journal of College Biology Teaching, 33, 11-18.

Vosniadou, S, \& Brewer, WF. (1992). Mental models of the Earth: a study of conceptual change in childhood. Cognitive Psychology, 24, 535-585.

Wellman, HM, \& Gelman, SA. (1998). Knowledge acquisition in foundational domains. In W. Damon, D. Kuhn, \& R. Siegler (Eds.), Handbook of child psychology (5th ed., Vol. 2. Cognition, perception and language) (pp. 523-574). New York, NY: Wiley.

Woods, CS, \& Scharmann, JC. (2001). High school students' perceptions of evolutionary theory. Electronic Journal of Science Education, 6.

\subsection{6/1936-6434-6-26}

Cite this article as: Walter et al:: Investigating the relationship between college students' acceptance of evolution and tree thinking understanding. Evolution: Education and Outreach 2013, 6:26

\section{Submit your manuscript to a SpringerOpen ${ }^{\odot}$ journal and benefit from:}

- Convenient online submission

- Rigorous peer review

- Immediate publication on acceptance

- Open access: articles freely available online

- High visibility within the field

- Retaining the copyright to your article

Submit your next manuscript at $\boldsymbol{\wedge}$ springeropen.com 